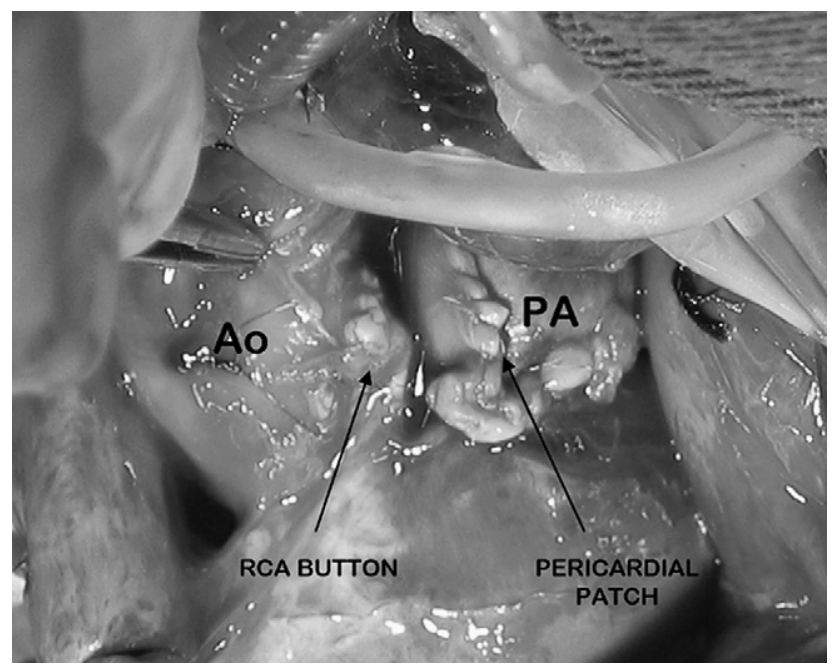

FIGURE 1. Translocated right coronary artery to the aortic side of the aortopulmonary window; pericardial patch is at the pulmonary side.

the September 2009 issue of this Jour$n a l$, Léobon and associates ${ }^{1}$ reported their clinical trial of 2 patients and options for the surgical treatment of the pathologic condition. Our group has also reported a successful surgical treatment for an infant with the same combination but with a novel technique. ${ }^{2}$

Our patient was a 4-month-old boy who had congestive heart failure and a continuous murmur on the left sternal border. Echocardiography and angiography showed APW and RCA originating from the pulmonary trunk. During the operation, after standart conduct of cardiopulmonary bypass, we made an incision in the APW toward the origin of RCA at the pulmonary end of the connection and prepared the proximal part of the RCA as a button ready for reimplantation. After ensuring that the origin of the left coronary artery was correct, we mobilized the proximal part of the RCA to avoid kinking. We then implanted the prepared RCA button to the aortic side of the transected APW with extreme care given to avoid kinking. To finish the procedure, we closed the defect at the pulmonary artery side with a pericardial patch (Figure 1). The postoperative course of the patient was uneventful with discharge on the sixth postoperative day.

The principal approach for definitive repair consists of transferring the RCA from the pulmonary artery to the aorta and closing the defect by a patch or a direct suture. ${ }^{1}$ However, in all these previosuly used methods there is always a need for an aortotomy to close the APW. Naturally, a second opening must be created for RCA implantation. Using the RCA button for closure of the defect at the aortic side may be a feasable option in patients with anatomic proximity of the RCA and APW. The most important point about this method is proximal mobilization of the RCA to avoid any kinking. We believe our succesful case suggests a different strategy for repair of this rare anomaly.

\section{Hakan Aydin} Ali Kutsal

The Department of Cardiovascular Surgery

Dr. Sami Ulus Children's Hospital Ankara, Turkey

\section{References}

1. Léobon B, Le Bret E, Roussin R, Kortas C, Ly M, Sigal-Cinqualbre A, et al. Technical options for the treatment of anomalous origins of right or left coronary arteries associated with aortopulmonary windows. J Thorac Cardiovasc Surg. 2009;138: 777-8.

2. Aydin H, Ozisik K, Surer S, Bolat A, Koc M, Kutsal A. Translocation of anomalous right coronary artery to aortic side of the aortopulmonary window: a different approach for a rare combination. J Card Surg. 2009;24:567-9.

doi:10.1016/j.jtcvs.2009.11.032

\section{Reply to the Editor:}

In their letter, Aydin and Kutsal report a new case of a right coronary artery originating from the pulmonary trunk associated with an aortopulmonary window in a 4-month old boy. They have corrected this anomaly with a modified technique of right coronary artery transfer, using the right coronary button to close the aortic wall defect. The pulmonary artery defect was closed with an autologous pericardial patch.

Owing to the anomalous site of implantation of the right coronary artery, transfer was preferable to rerouting, as suggested in our article. ${ }^{1}$ The use of the coronary artery button to close the aortic wall defect is seducing because of the quality of this autologous arterial tissue, allowing a complete repair without prosthetic material.

However, the implantation of the right coronary artery, exactly in the place where the aorta faces the pulmonary artery, may create an interaortopulmonary route of the initial part of this vessel. This could result in coronary compression in these very young patients, who may have postoperative pulmonary hypertension. Thus, my colleagues and I prefer to implant the right coronary artery where it seems, after mobilization, the most suitable on the anterior wall the aorta and to close the aortopulmonary window in a conventional manner.

Bertrand Léobon, $M D, P h D$

Department of Cardiovascular

Surgery $B$

University Hospital of Rangueil

Toulouse, France

\section{Reference}

1. Léobon B, Le Bret E, Roussin R, Kortas C, Ly M, Sigal-Cinqualbre A, et al. Technical options for the treatment of anomalous origins of right or left coronary arteries associated with aortopulmonary windows. J Thorac Cardiovasc Surg. 2009;138: 777-8.

doi:10.1016/j.jtcvs.2009.11.033 